\title{
Phase II study of preoperative radiation plus concurrent daily tegafur-uracil (UFT) with leucovorin for locally advanced rectal cancer
}

Patrice Cellier ${ }^{1}$, Bernard Leduc ${ }^{2}$, Laurent Martin ${ }^{3}$, Brigitte Vié ${ }^{4}$, Christian Chevelle ${ }^{5}$, Véronique Vendrely ${ }^{6}$, Augustin Salemkour ${ }^{7}$, Christian Carrie ${ }^{8}$, Gilles Calais ${ }^{9}$, Pascal Burtin ${ }^{10}$, Loïc Campion $^{11}$, Michèle Boisdron-Celle $1,2,3,4,5,6,7,7,9,9,10,11,12$, Alain Morel ${ }^{1,2,3,4,5,6,7,7,9,9,10,11,12}$, Virginie Berger ${ }^{1 *}$,

Erick Gamelin $1,2,3,4,5,6,7,8,9,10,11,12$

\begin{abstract}
Background: Considerable variation in intravenous 5-fluorouracil (5-FU) metabolism can occur due to the wide range of dihydropyrimidine dehydrogenase (DPD) enzyme activity, which can affect both tolerability and efficacy. The oral fluoropyrimidine tegafur-uracil (UFT) is an effective, well-tolerated and convenient alternative to intravenous 5-FU. We undertook this study in patients with locally advanced rectal cancer to evaluate the efficacy and tolerability of UFT with leucovorin (LV) and preoperative radiotherapy and to evaluate the utility and limitations of multicenter staging using pre- and post-chemoradiotherapy ultrasound. We also performed a validated pretherapy assessment of DPD activity and assessed its potential influence on the tolerability of UFT treatment.
\end{abstract}

Methods: This phase II study assessed preoperative UFT with LV and radiotherapy in 85 patients with locally advanced T3 rectal cancer. Patients with potentially resectable tumors received UFT ( $300 \mathrm{mg} / \mathrm{m} / 2 /$ day), LV (75 mg/ day), and pelvic radiotherapy (1.8 Gy/day, 45 Gy total) 5 days/week for 5 weeks then surgery 4-6 weeks later. The primary endpoints included tumor downstaging and the pathologic complete response ( $p C R$ ) rate.

Results: Most adverse events were mild to moderate in nature. Preoperative grade $3 / 4$ adverse events included diarrhea $(n=18,21 \%)$ and nausea/vomiting $(n=5,6 \%)$. Two patients heterozygous for dihydropyrimidine dehydrogenase gene (DPYD) experienced early grade 4 neutropenia (variant IVS14+1G $>$ A) and diarrhea (variant $2846 \mathrm{~A}>\mathrm{T}$ ). Pretreatment ultrasound TNM staging was compared with postchemoradiotherapy pathology TN staging and a significant shift towards earlier TNM stages was observed $(p<0.001)$. The overall downstaging rate was $42 \%$ for primary tumors and $44 \%$ for lymph nodes. The pCR rate was $8 \%$. The sensitivity and specificity of ultrasound for staging was poor. Anal sphincter function was preserved in 55 patients (65\%). Overall and recurrence-free survival at 3 years was $86.1 \%$ and $66.7 \%$, respectively. Adjuvant chemotherapy was administered to 36 node-positive patients (mean duration 118 days).

Conclusion: Preoperative chemoradiotherapy using UFT with LV plus radiotherapy was well tolerated and effective and represents a convenient alternative to 5-FU-based chemoradiotherapy for the treatment of resectable rectal cancer. Pretreatment detection of DPD deficiency should be performed to avoid severe adverse events.

\footnotetext{
* Correspondence: v.berger@angers.fnclcc.fr

${ }^{1}$ Centre Paul Papin, 2 rue Moll, 49933 Angers cedex 9, France

Full list of author information is available at the end of the article
} 


\section{Background}

The standard approach for the preoperative treatment of rectal cancer is intravenous (i.v.) 5-fluorouracil (5-FU)based chemoradiotherapy [1-3] (Rich et al, 1995; Lawrence et al, 1997; Bosset et al 2000). 5-FU can be administered as either a bolus injection or a continuous infusion [4] [Smalley 2006]. However, continuous infusion requires specialized pumps, which are inconvenient for patients, and long-term venous access, which makes patients susceptible to infections and thrombosis $[1,2]$ (Rich et al, 1995; Bosset et al, 2000).

The oral fluoropyrimidine UFT (tegafur-uracil) is an effective, well-tolerated and convenient alternative to i.v. 5 -FU that is widely used in the treatment of colorectal cancer [5] (Borner et al, 2002). A phase I study of preoperative UFT with leucovorin (LV) with radiotherapy identified a maximum tolerated dose of UFT of $350 \mathrm{mg} /$ $\mathrm{m}^{2} /$ day with LV $90 \mathrm{mg} /$ day [6] (Hoff et al, 2000). In phase II and III trials, UFT $\left(200-350 \mathrm{mg} / \mathrm{m}^{2} /\right.$ day) without or with LV (15-45 mg/day) and preoperative radiotherapy (45-50.4 Gy) has shown similar tumor response and downstaging rates to those using continuous infusion 5FU [7-14] (de la Torre et al, 1999, de la Torre et al, 2008 Feliu et al, 2002; Wang et al, 2005; Fernández-Martos et al, 2004; Girault 2008; Kundel 2007; Vestermark 2008).

Considerable variation in 5-FU metabolism and outcome due to the wide range of dihydropyrimidine dehydrogenase (DPD) enzyme activity has been observed and this variability can influence both tolerability and response to cancer chemotherapy [15] (Seck et al, 2005). Although deficient DPD activity is rare (approximately 3-5\% of patients), patients with this deficiency may experience severe and life-threatening adverse events following treatment with 5-FU or oral fluoropyrimidines such as capecitabine [16-18] (Diasio and Johnson, 1999; Van Kuilenburg et al, 2003; Saif and Diasio, 2006).

We undertook the present multicenter study in patients with locally advanced rectal cancer to evaluate the efficacy and tolerability of UFT with LV and preoperative radiotherapy and to evaluate the utility and limitations of multicenter staging using pre- and post-chemoradiotherapy ultrasound. Since little information is available regarding DPD activity in UFT-treated patients with rectal cancer, we also performed a validated pretherapy assessment of DPD activity and assessed its potential influence on the tolerability of UFT treatment.

\section{Methods \\ Patients}

Eligible patients had pathologically confirmed clinically resectable stage T3-T4 and N0-N2 adenocarcinoma of the distal rectum with no distant metastases. Entry criteria were: inferior margin within $15 \mathrm{~cm}$ of the anal verge and palpable on digital examination; World Health Organization (WHO) performance status 0-2; age 18-80 years; adequate hematologic (neutrophils $>1500 / \mathrm{mm}^{3}$ ), hepatic (bilirubin $<2$ upper normal limit), and renal (creatinine $<150 \mu \mathrm{mol} / \mathrm{L}$ ) function. Patients with prior malignancies (excluding localized epithelial skin or cervical cancer), chemotherapy, and/or pelvic radiotherapy were excluded. The study was approved by local ethics committees and was conducted according to the Declaration of Helsinki. Written informed consent was obtained from each patient before enrollment.

Pretreatment evaluation included a complete medical history and physical examination (including digital rectal examination), complete blood count and chemistry profile, electrocardiogram, detection of DPD activity (requiring a 10 days period), endorectal ultrasound (EUS), endoscopy with biopsy, chest X-ray, and abdomen-pelvis computed tomography (CT) scan.

\section{Treatment}

Chemotherapy consisted of UFT $300 \mathrm{mg} / \mathrm{m}^{2} /$ day and LV $75 \mathrm{mg} /$ day orally in three divided doses taken at approximately 8 -hour intervals (either 1 hour before or at least 1 hour after food), 5 days/week for 5 weeks (days 1-33). Pelvic radiotherapy (daily dose $1.8 \mathrm{~Gy}$ ), delivered concurrently with chemotherapy, was delivered using a conventional four-field box technique (anterior and posterior fields, plus right and left lateral fields) and with a minimum of 10 megavoltage photons. A total dose of $45 \mathrm{~Gy}$ was delivered to the isocenter of the four fields. The planning target volume was defined as the clinical target volume, i.e. the primary tumor, iliac lymph nodes, and mesorectum in toto, plus a 10-15 mm margin. Diagnostic imaging was used to define the gross target volume.

Surgical resection was performed 4-6 weeks after completion of chemoradiotherapy using a standardized technique with mesorectal excision. Postoperative chemotherapy could be prescribed for patients who were lymph-node positive and who responded to preoperative treatment. These patients received 5 cycles of the same UFT with LV regimen or 5-FU/LV (de Gramont or Mayo clinic regimens) 3-6 weeks after surgery.

\section{Toxicity assessment and dose adjustments}

Toxicity, graded using WHO criteria for chemotherapy and early radiotherapy toxicity, was assessed at weekly clinic and biologic examinations during chemoradiotherapy and at the end of treatment [19] (Miller et al, 1981). Late radiotherapy toxicity was graded according to the SOMA-LENT criteria [20] (Mornex et al, 1997). In the event of grade 2-4 adverse events, chemotherapy was withheld until evidence of hematologic recovery (neutrophils $\geq 1500 / \mathrm{mm}^{3}$ and platelets $\geq 100000 / \mathrm{mm}^{3}$ ) and 
complete resolution of all nonhematologic adverse events (other than alopecia) to baseline or grade 1. The UFT dose was reduced by one capsule per day if grade $3 / 4$ toxicity occurred. Radiotherapy was postponed for 1-2 weeks in the event of grade 3 diarrhea that persisted despite UFT discontinuation; radiotherapy was stopped if the grade 3/4 diarrhea persisted for longer than 2 weeks.

\section{Evaluation of response}

EUS, chest X-ray, and CT scan were performed at baseline (within 15 days before chemoradiotherapy) and after the end of chemoradiotherapy (within 7 days before surgery). Echoendoscopic and pathologic stages were defined using the tumor node metastasis (TNM) staging system (version 5.0) [21] (Sobin and Wittekind, 1997). Initially, it was planned to determine tumor downstaging by comparing posttreatment ultrasound $(\mathrm{u})$ TNM stage (EUS) with the preoperative uTNM stage. However, due to the limitations of preoperative EUS because of inflammatory effects and tissue modifications and the limited number of assessable patients, we focused on pathological results and compared posttreatment pathological (p)TNM stage to preoperative uTNM stage. Primary tumor and node downstaging were defined as reductions in $\mathrm{T}$ and $\mathrm{N}$ stages by at least one level. No response was defined as similar pTNM and uTNM classifications. A pCR was defined as the absence of any residual tumor cells in the operative specimen [22] (Meterissian et al, 1994). Lymph nodes were examined after treatment with a clarification solution in order to aid detection and improve the reliability of the pathologic $\mathrm{N}$ staging. All resected specimens from the different hospitals were centralized and reexamined in a reference pathology laboratory for a central review.

Sphincter function was scored according to the Memorial Sloan Kettering Cancer Center scale [23] (Minsky et al, 1995). Progression-free survival (PFS) and overall survival (OS) were measured from the time of inclusion to the time of disease progression and death (or last follow-up), respectively.

\section{Detection of DPD activity}

$D P Y D$ genotyping included examination of 24 relevant gene variants potentially involved in DPD deficiency. Single nucleotide polymorphisms (SNPs) were detected using a real-time mini-sequencing method [24] (Morel et al, 2005). Dihydrouracil and uracil plasma concentrations were determined simultaneously using a liquid chromatography method [25] (Remaud et al, 2005); if DPD deficiency was suspected, the plasma dihydrouracil: uracil $\left(\mathrm{UH}_{2}: \mathrm{U}\right)$ ratio was determined [26] (Boisdron-Celle et al, 2007). $\mathrm{UH}_{2}: \mathrm{U}$ ratios were assessed as previously described [27] (Gamelin et al, 1999). When DPD deficiency was identified, UFT was administered at the planned dose but both the clinician and patient were informed of the risk associated with treatment and appropriate precautions were taken, such as careful monitoring of diarrhea and neutropenia.

\section{Statistics}

Using a two-stage design [28] (Simon, 1989) and assuming a tumor downstaging rate of at least $25 \%$, with alpha and beta errors of $5 \%$ and $10 \%$, respectively, 41 patients were to be enrolled in the first stage of the study. If four or fewer responses were observed, the treatment would be considered ineffective and the trial would be stopped. If five or more responses were observed, 29 additional patients would be enrolled, for a total of 70 patients. As numerous patients were not assessable for EUS, 15 additional patients were recruited with the approval of IERB.

The primary endpoint was the tumor downstaging rate with 95\% confidence interval (CI). Results are expressed as mean \pm standard deviation. Quantitative variables were compared using the nonparametric Mann-Whitney test and qualitative variables using Pearson's chi-squared test or Fisher's exact test. Survival distributions were estimated using the Kaplan-Meier methodology. For safety analyses, the worst toxicity grade per patient in all chemotherapy cycles was used. All statistical analyses were conducted using Statistical Package for Social Sciences software (SPSS version 10.0, Chicago, IL, USA).

\section{Results}

Eighty-five patients were enrolled at 15 centers between July 2002 and January 2004. Eight patients were ineligible at study entry: four patients had one or more major protocol violations (liver metastases, $\mathrm{n}=3$; suspicion of pulmonary metastases, $\mathrm{n}=1$; other cancer, $\mathrm{n}=1$ ) and six patients had one or more minor protocol violations (tumor in the upper rectum, $\mathrm{n}=4$; age $>80$ years, $\mathrm{n}=1$; vesical papilloma, $\mathrm{n}=1$ ). All 85 patients were evaluated according to the intention-to-treat principle.

\section{Patient characteristics}

Patient characteristics at baseline are shown in Table 1. Four of the 24 known variants of the DPYD gene were identified. One patient was heterozygous for the $-1590 \mathrm{~T}$ $>\mathrm{C} \mathrm{SNP}$ in the promoter region, one was heterozygous for IVS14+1G > A (G1A [DPYD*2A]), one had 2846A > $\mathrm{T}$ (D949V), and a fourth had $1679 \mathrm{~T}>\mathrm{G}$. A further 38 patients were heterozygous for $85 \mathrm{~T}>\mathrm{C}$. Uracil plasma levels were higher than the threshold $(15 \mu \mathrm{g} / \mathrm{L})$ [26] (Boisdron-Celle et al, 2007) in three of four patients with variant DPYD (IVS14+1G > A: $36 \mu \mathrm{g} / \mathrm{L} ; 2846 \mathrm{~A}>$ $\mathrm{T}: 19 \mu \mathrm{g} / \mathrm{L}$; and $1679 \mathrm{~T}>\mathrm{G}: 25 \mu \mathrm{g} / \mathrm{L})$. 
Table 1 Baseline patient characteristics

\begin{tabular}{lc}
\hline Parameter & $\begin{array}{c}\text { Number of patients (\%) } \\
\mathbf{N}=\mathbf{8 5}\end{array}$ \\
\hline Age (years) & 67.1 \\
Median & $25-81$ \\
$\quad$ Range & \\
Gender & $56(66)$ \\
$\quad$ Male & $29(34)$ \\
Female & \\
Clinical TNM stage & $85(100)$ \\
T3 & $47(55)$ \\
NO & $33(39)$ \\
N1 & $2(2)$ \\
N2 & $3(4)$ \\
Unknown & \\
Tumor staging method & $66(78)$ \\
EUS & $11(13)$ \\
Rigid rectoscopy & $7(8)$ \\
Other & $1(1)$ \\
Unknown & \\
Distance from anal verge & $50(59)$ \\
$>5$ cm & $32(38)$ \\
$\leq 5$ cm & $3(4)$ \\
Unknown & \\
WHO performance status & $75(88)$ \\
0 & $9(11)$ \\
1 & $1(1)$ \\
\hline Unknown &
\end{tabular}

TNM = tumor node metastasis.

$\mathrm{WHO}=$ World Health Organization .

\section{Treatment}

Sixty-three patients (74\%) completed treatment as planned. Most patients (92\%) received the planned dose of radiotherapy (median dose 45 Gy, range 18-46.8 Gy). Radiotherapy was postponed for at least 1 day in 66 patients (78\%); dose reductions were drug related in five patients $(6 \%)$. The planned UFT dose was delivered in 48 patients (mean dose $\left.294 \pm 24 \mathrm{mg} / \mathrm{m}^{2}\right)$. Chemotherapy was delayed in nine patients $(11 \%)$ and the dose was reduced in 15 patients $(18 \%)$ as a result of adverse events, including diarrhea $(\mathrm{n}=$ $5)$, nausea/vomiting $(\mathrm{n}=1)$, stroke $(\mathrm{n}=1)$, dehydration $(\mathrm{n}=$ $3)$, and gastrointestinal effects $(n=1)$. Only four $(5 \%)$ of the 85 patients did not undergo surgery: one patient died of a cerebrovascular stroke (unrelated to treatment) during the preoperative period; one patient was lost to follow-up; and the primary tumor was unresectable in two patients because of local progression. The majority of patients underwent anterior resection (AR) $(\mathrm{n}=54 ; 63 \%)$; abdominoperineal resection (APR) was necessary in 27 patients $(32 \%)$.

\section{Safety}

Diarrhea was the most common adverse event (60 events, 42 of which were judged to be treatment related). Most adverse events were mild to moderate in nature. Grade $3 / 4$ adverse events, which occurred in 38 patients (45\%), are shown in Table 2 . Only patients who were heterozygous for variants IVS14+1G > A and 2846A > T experienced very early grade 4 neutropenia and diarrhea related to UFT. The patient who was heterozygous for variant $1679 \mathrm{~T}>\mathrm{G}$ experienced grade 4 diarrhea related to treatment at week 3 and was withdrawn.

\section{Downstaging, pathologic response, and sphincter preservation}

EUS was available pre- and posttreatment for 66 patients and was interpretable in 52 evaluable patients (61\%). Postchemotherapy uTN staging was in agreement with double-checked pTN staging in 26 of 52 patients (50\%) (Table $3)$. Pretreatment uTNM staging was compared with postchemoradiotherapy pTN staging (Table 4) and a significant shift towards earlier TNM stages was observed ( $\mathrm{p}<$ 0.001). Downstaging of the primary tumor occurred in $22 / 52$ patients (42\%) and downstaging of the lymph nodes occurred in $23 / 52$ patients (44\%). In the 46 patients assessable for $\mathrm{T}$ and $\mathrm{N}$ stage, 11 patients (24\%) had downstaged tumor and nodes, 11 patients (24\%) had downstaged nodes only, nine patients (20\%) had downstaged tumor only, and there was no difference in $\mathrm{T}$ or $\mathrm{N}$ staging in 15 patients (33\%). The overall downstaging rate was $44 \%$ for primary tumors and $48 \%$ for lymph nodes. A centralized second pathologic examination performed in 78 patients confirmed the initial pTN results in $77 \%$ of cases.

Table 2 Acute adverse events that occurred during preoperative chemoradiotherapy

\begin{tabular}{|c|c|c|}
\hline \multirow[b]{2}{*}{ Adverse event } & \multicolumn{2}{|c|}{$\begin{array}{l}\text { Number of patients (\%) } \\
\qquad \mathrm{N}=85\end{array}$} \\
\hline & Grade 3 & Grade 4 \\
\hline Diarrhea & $14(17)$ & $4(5)$ \\
\hline Nausea/vomiting & $4(5)$ & $1(1)$ \\
\hline Cerebrovascular event & 0 & $2(2)$ \\
\hline Proctitis & $1(1)$ & 0 \\
\hline Radiocystitis & $1(1)$ & 0 \\
\hline Radiodermatitis & $2(2)$ & 0 \\
\hline Anemia & $1(1)$ & 0 \\
\hline Leukopenia & 0 & $1(1)$ \\
\hline Neutropenia & 0 & $1(1)$ \\
\hline Hand-foot syndrome & 0 & 0 \\
\hline Mucositis & $1(1)$ & 0 \\
\hline Subocclusive syndrome & $1(1)$ & 0 \\
\hline Second-degree cutaneous burns* & $1(1)$ & 0 \\
\hline Epistaxis & $1(1)$ & 0 \\
\hline Pneumopathy & $1(1)$ & 0 \\
\hline Thrombophlebitis & $1(1)$ & 0 \\
\hline Total & $29(34)$ & $8(9)$ \\
\hline
\end{tabular}

1. *Not related to treatment. 
Table 3 Post-treatment EUS T staging and pathologic analysis $\mathrm{T}$ staging

\begin{tabular}{lccccc}
\hline & \multicolumn{4}{c}{ Pathologic analysis } \\
\hline Number of patients (\%) & T0 & T2 & T3 & Total \\
\hline EUS & T0 & $3(43)$ & - & $4(57)$ & 7 \\
& T1 & $1(50)$ & - & $1(50)$ & 2 \\
T2 & $3(20)$ & $4(27)$ & $8(53)$ & 15 \\
T3 & - & $8(30)$ & $19(70)$ & 27 \\
& Total & 7 & 12 & 32 & 51 \\
\hline
\end{tabular}

EUS = endorectal ultrasonography.

For nine patients, the first pathologic examination was understaged (four pT0, three pT1, two pT2, and one pT3), and for three patients it was overstaged (two pT2 and one pT4). Two patients with nonspecified $T$ stage were classified pT3. In seven patients, malignant cells were undetectable in both the primary tumor and lymph nodes giving a pCR rate of $8 \%$. Ten patients (12\%) had some microscopic residual disease (Tmic).

Anal sphincter function was preserved in 55 patients (65\%). Five of 60 patients initially deemed suitable for anterior resection (AR) had an abdominoperineal resection (APR) (8\% of planned resections) and two of 23 patients whose planned surgery was APR underwent an AR (9\% of planned resections). APR was performed in $60 \%$ of patients $(n=21)$ with a tumor in the distal third of the rectum and in $9 \%$ of patients $(\mathrm{n}=4)$ with a tumor in the middle third of the rectum (within $6-8 \mathrm{~cm}$ of the pectineal line) due to an overestimated distance to the anal verge and to infiltration of the surgical border. AR was performed in $87 \%$ of patients $(n=41)$ with a tumor in the middle third of the rectum and in $40 \%$ of those whose tumor was in the distal third $(\mathrm{n}=14)$ (unknown pectineal line $\mathrm{n}=2$, inextirpable $\mathrm{n}=2$ ). Perioperative and 30 -day postoperative complications included anastomotic leakage $(\mathrm{n}=1)$, perineal complications $(\mathrm{n}=1)$, bleeding $(\mathrm{n}=1)$, ileus $(\mathrm{n}=1)$, fistula $(\mathrm{n}=1)$, and death $(\mathrm{n}=2)$.

Table 4 Pre-treatment EUS $\mathrm{T}$ and $\mathrm{N}$ staging and posttreatment pathologic $\mathbf{T}$ and $\mathbf{N}$ staging in resected patients

\begin{tabular}{|c|c|c|c|c|c|}
\hline \multirow{2}{*}{$\begin{array}{l}\text { Pre-treatment } \\
\text { EUS T stage }\end{array}$} & \multicolumn{4}{|c|}{$\begin{array}{l}\text { Post-treatment pathologic } \\
\text { stage }\end{array}$} & \multirow[t]{2}{*}{ Downstaging, n/N (\%) } \\
\hline & pTO & pT1 & pT2 & pT3 & \\
\hline $\mathrm{T} 2^{*}$ & 1 & 0 & 2 & 0 & 1/3 (33) \\
\hline $\mathrm{T} 3$ & 6 & 2 & 13 & 28 & $21 / 49(43)$ \\
\hline Total & 7 & 2 & 15 & 28 & $22 / 52(42)$ \\
\hline EUS $N$ stage & pNO & $\mathrm{pN} 1$ & & & \\
\hline NO & 19 & 0 & & & $0 / 19$ \\
\hline N1 & 22 & 10 & & & 22/32 (69) \\
\hline N2 & 0 & 1 & & & $1 / 1(100)$ \\
\hline Total & 41 & 11 & & & $23 / 52(44)$ \\
\hline
\end{tabular}

EUS = endorectal ultrasonography.

*Three patients had an estimated T2 tumor using EUS but had a T3 tumor identified clinically.

\section{Survival and recurrence}

The mean follow-up time was 45 months (range 1 - 84 months; one patient was lost to follow-up). OS was $92.6 \%$ at 1 year $86.1 \%$ at 2 years and $83.2 \%$ at 3 years; mean recurrence-free survival was $39 \pm 24$ months. Recurrence free survival was $81.9 \%$ at 1 year, $70.7 \%$ at 2 years and $66.7 \%$ at 3 years.

Two patients died within 18 days of surgery (one had a pulmonary embolism and the other had a cerebrovascular stroke). Sixteen other patients died during the study: twelwe due to progressive disease; one due to diabetic decompensation, one due to vascular cerebral stroke that occurred before surgery, and one due to acute pulmonary failure and one due to a fall.

The level of local control in the 81 patients who underwent surgery was $95 \%$, with four patients $(5 \%)$ having local recurrence and 20 (24.7\%) having secondary metastases. Regardless of location, relapse generally occurred $<1$ year after surgery (mean: $346 \pm 236$ days).

\section{Adjuvant chemotherapy}

Following surgery, 36 of 79 eligible patients (46\%) received adjuvant chemotherapy (mean duration $118 \pm$ 65.8 days): 21 patients (58\%) received 5-FU-based chemotherapy, 10 (28\%) received UFT-based chemotherapy and 4 (11) received oxaliplatin-based chemotherapy. Six patients had further chemotherapy for metastatic disease within 4 months of surgery.

\section{Discussion}

Preoperative radiotherapy with or without i.v. 5-FU is a reference treatment for patients with rectal cancer. The aim of the present study was to evaluate the efficacy and tolerability of the combination of UFT-based chemotherapy and radiotherapy before resection. We found a significant downstaging rate (44\% for primary tumors and $48 \%$ for lymph nodes) similar to capecitabine [29] (Kim et al, 2007). The pCR rate was $8 \%$, which is similar to that previously reported [11,30,31] (Fernández-Martos et al, 2004; Sauer et al, 2004; Durnst et al, 2008). The sphincter preservation rate was also high (65\%). The 2-year OS rate was $80 \%$, with $75 \%$ of patients free from recurrence, and the rate of local relapse was $5 \%$. These results are similar to those obtained in other trials, many of which used more aggressive regimens, such as combination oxaliplatin and fluoropyrimidine-based chemoradiotherapy [32-34] (Sebag-Montefiore et al, 2005; Calvo et al, 2006; Ryan et al, 2006).

Although the primary objective of this study was to determine the downstaging of tumor and lymph nodes by comparing EUS before and after chemoradiotherapy, we decided to compare the initial EUS to pathological findings. The accuracy of EUS, which was mandatory for pretreatment evaluation in our study, has been 
reported to range from $62-66 \%$ for the assessment of rectal wall penetration and $23 \%$ for the determination of nodal status [35,36] (Janjan et al, 1999; Chan et al, 2005). However, EUS is not possible in circumferential tumors with stenosis and it is generally difficult to interpret 6 weeks after completion of chemoradiotherapy. In addition, EUS is highly dependent on the operator and consistency of results can be an issue in multicenter trials. The nonspecific inflammatory effects and deep alterations evident in tissue architecture after chemoradiotherapy make this examination useless after treatment, despite its importance in determining the extent of the tumor before surgery. Thus, we compared the initial echoendoscopy with the pathologic exam $[37,38]$ (Chan et al, 2005; Mawdsley et al, 2005). Sensitivity and specificity were not good even at the first pretreatment examination: some tumors initially staged as $\mathrm{T} 0$ or $\mathrm{T} 1$ by EUS were found to be T3 on pathologic examination. Based on evidence from the literature and our own experience, the current practice in our institutions is to use magnetic resonance imaging for the evaluation of local and regional tumor extension, as it provides more precise and reliable results [38,39] (Rasheed et al, 2006; Muthusamy et al, 2007).

The tolerability of the UFT chemoradiotherapy was acceptable and diarrhea, as expected, was the most common adverse event. Two patients with heterozygous variants (IVS14+1G > A and 2846A > T) plus the phenotype of major enzyme deficiency experienced grade 4 neutropenia and diarrhea. At the time this study was undertaken, no data were available to link specific DPD deficiencies and severe UFT-related adverse events. Therefore, no dose adjustments were specified in the protocol for patients with particular gene variations, and two patients had grade 4 adverse events that might have been avoided. Armed with this information, however, we now systematically test for DPD by both DPD gene variants and $\mathrm{UH}_{2}: \mathrm{U}$ ratio before beginning UFT-based treatment and reduce the UFT dose in patients with major enzyme deficiencies as we do for all i.v. and oral fluoropyrimidine therapy [26] (Boisdron-Celle et al, 2007).

The pattern of relapse in patients with locally advanced rectal cancer and the tolerability of treatment $[37,38]$ (Mawdsley et al, 2005; Rasheed et al, 2006) call into question the approach to preoperative intensification of chemoradiotherapy currently under investigation elsewhere. In our study, only $5 \%$ of patients experienced a local relapse similar to that observed by other authors [40,41] (Gérard et al, 2006; Bosset et al, 2006).

On the other hand, $15 \%$ of the patients died due to distant secondary metastases. Thus, the challenge that remains following chemoradiotherapy for locally advanced rectal cancer is to control distant metastases. In colon cancer, the risk of distant metastasis is reduced with adjuvant chemotherapy and this might also apply to the rectal cancer setting. Many authors have emphasized the negative impact of neoadjuvant chemoradiotherapy toxicity on compliance with and tolerability of adjuvant chemotherapy [42,43] (Rodríguez-Ramírez et al, 2006; Urso et al, 2006). In our study, the mean duration of adjuvant chemotherapy was 4 months, somewhat less than the 6 months usually planned for other tumors, even though UFT has a favorable tolerability profile, better than the other combinations usually reported. Our opinion is that patients would gain more benefit from an efficient adjuvant or perhaps neoadjuvant combination therapy than an intensification of chemoradiotherapy by adding a cytotoxic drug to a fluoropyrimidine [44,45] (Chen et al, 2007; Bosset et al, 2008). Interest in preoperative chemoradiotherapy for patients with locally advanced rectal cancer is due to the potential for tumor downstaging, which increases the likelihood of curative surgery and allows sphincter preservation in many patients with low-lying tumors. UFT has the advantage of convenient oral administration and a very good tolerability profile, with no hand-foot syndrome.

The efficacy and tolerability of UFT-based chemoradiotherapy reported here are comparable with those previously reported for other fluoropyrimidines and much better than those reported with cytotoxic drug combinations. In addition, detection of DPD deficiency, which is legally recommended for all fluoropyrimidines, has the potential to allow identification of patients with clinically relevant enzyme deficiencies and prevent severe acute adverse events related to this condition.

\section{Conclusion}

Although EUS post chemoradiotherapy failled to assess downstaging, preoperative UFT is an effective, well tolerated, and convenient treatment option for patients with locally advanced rectal cancer.

\section{Acknowledgements}

We thank Kevin De-Voy who provided medical writing services on behalf of Merck Serono.

This work was supported in part by a grant from Bristol Myers-Squibb Oncology.

\section{Author details}

${ }^{1}$ Centre Paul Papin, 2 rue Moll, 49933 Angers cedex 9, France. ${ }^{2}$ Centre Hospitalier, Boulevard d DocteurVerlhac, 19312 Brive la Gaillarde Cedex, France. ${ }^{3}$ Centre Guillaume le Conquérant, 29 rue Guillaume le Conquérant, 76600 Le Havre, France. ${ }^{4}$ Centre François Baclesse, Avenue du Général Harris, BP 5026, 1407 Caen Cedex 5, France. ${ }^{5}$ Clinique Pasteur, 45 avenue de Lombez, BP 27617, 31076 Toulouse Cedex 3, France. ${ }^{6}$ Groupe Hospitalier Saint-André, 1 rue Jean Burguet, 33000 Bordeaux, France. ${ }^{7}$ Centre d'OncoRadiothérapie d'Eure et Loire, 4 rue Claude Bernard (site Fontenoy), B.P. 1030928600 Chartres, France. ${ }^{8}$ Centre Léon Bérard, 28 rue Laennec, 69373 Lyon Cedex 8, France. ${ }^{9} \mathrm{CHU}$ Bretonneau, CORAD 2 Boulevard Tonnelé, 37044 Tours Cedex, France. ${ }^{10}$ Centre Hospitalier Universitaire, 4 rue Larrey, 49933 Angers Cedex 9, France. ${ }^{11}$ Centre René Gauducheau, Bd Jacques Monod, 44805 Nantes St Herblain Cedex, France. ${ }^{12}$ CRCNA INSERM U892, 1, quai de Tourville BP 13522, 44035 Nantes Cedex 1, France. 


\section{Authors' contributions}

$P C, B L, L M, B V, C C, W, A S, C C, G C, P B$ enrolled patients in the trial PC, VB, EG conceived of the study, and participated in its design and coordination. LC participated in the study design and performed the statistical analysis. MBC AM carried out the molecular and genetic studies. VB drafted the manuscript. All authors read and approved the final manuscript

\section{Competing interests}

The authors declare that they have no competing interests.

Received: 30 July 2010 Accepted: 16 March 2011

Published: 16 March 2011

\section{References}

1. Rich TA, Skibber JM, Ajani JA, Buchholz DJ, Cleary KR, Dubrow RA, Levin B, Lynch PM, Meterissian SH, Roubein LD, Ota DM: Preoperative infusional chemoradiation therapy for stage T3 rectal cancer. Int J Radiat Oncol Biol Phys 1995, 32:1025-9

2. Bosset JF, Magnin V, Maingon P, Mantion G, Pelissier EP, Mercier M, Chaillard G Horiot JC: Preoperative radiochemotherapy in rectal cancer: long-term results of a phase II trial. Int J Radiat Oncol Biol Phys 2000, 46:323-7.

3. Lawrence TS, Tepper JE, Blackstock AW: Fluoropyrimidine-radiation interactions in cells and tumors. Semin Radiat Oncol 1997, 7:260-6.

4. Smalley SR, Benedetti JK, Williamson SK, Robertson JM, Estes NC, Maher T, Fisher B, Rich TA, Martenson JA, Kugler JW, Benson AB, Haller DG, Mayer RJ, Atkins JN, Cripps C, Pedersen J, Periman PO, Tanaka MS Jr, Leichman CG, Macdonald JS: Phase III trial of fluorouracil-based chemotherapy regimens plus radiotherapy in postoperative adjuvant rectal cancer: $\mathrm{Gl}$ INT 0144. J Clin Oncol 2006, 24:3542-7.

5. Borner MM, Schöffski P, de Wit R, Caponigro F, Comella G, Sulkes A, Greim G, Peters GJ, van der Born K, Wanders J, de Boer RF, Martin C, Fumoleau P: Patient preference and pharmacokinetics of oral modulated UFT versus intravenous fluorouracil and leucovorin: a randomised crossover trial in advanced colorectal cancer. Eur J Cancer 2002, 38:349-58.

6. Hoff PM, Janjan N, Saad ED, Skibber J, Crane C, Lassere Y, Cleary KR, Benner S, Randolph J, Abbruzzese JL, Pazdur R: Phase I study of preoperative oral uracil and tegafur plus leucovorin and radiation therapy in rectal cancer. J Clin Oncol 2000, 18:3529-34.

7. de la Torre A, Ramos S, Valcárcel FJ, Candal A, Regueiro CA, Romero J, Magallón R, Salinas J, de las Heras M, Veiras C, Tisaire JL, Aragón G: Phase II study of radiochemotherapy with UFT and low-dose oral leucovorin in patients with unresectable rectal cancer. Int J Radiat Oncol Biol Phys 1999, 45:629-34

8. de la Torre A, García-Berrocal Ml, Arias F, Mariño A, Valcárcel F, Magallón R, Regueiro CA, Romero J, Zapata I, de la Fuente C, Fernández-Lizarbe E, Vergara G, Belinchón B, Veiras M, Molerón R, Millán I: Preoperative chemoradiotherapy for rectal cancer: randomized trial comparing oral uracil and tegafur and oral leucovorin vs. intravenous 5-fluorouracil and leucovorin. Int J Radiat Oncol Biol Phys 2008, 70:102-10

9. Feliu J, Calvillo J, Escribano A, de Castro J, Sánchez ME, Mata A, Espinosa E, García Grande A, Mateo A, González Barón M: Neoadjuvant therapy of rectal carcinoma with UFT-leucovorin plus radiotherapy. Ann Oncol 2002, 13:730-6.

10. Wang LW, Yang SH, Lin JK, Lin TC, Chan WK, Chen WS, Wang HS, Jiang JK, Lee RC, Li AF, Chao Y, Chi KH, Yen SH: Preoperative chemoradiotherapy with oral tegafur-uracil and leucovorin for rectal cancer. J Surg Oncol 2005, 89:256-64

11. Fernández-Martos C, Aparicio J, Bosch C, Torregrosa M, Campos JM, Garcera S, Vicent JM, Maestu I, Climent MA, Mengual JL, Tormo A, Hernandez A, Estevan R, Richart JM, Viciano V, Uribe N, Campos J, Puchades R, Arlandis F, Almenar D: Preoperative uracil, tegafur, and concomitant radiotherapy in operable rectal cancer: a phase II multicenter study with 3 years' follow-up. J Clin Oncol 2004, 22:3016-22.

12. Vestermark LW, Jacobsen A, Qvortrup C, Vestermark LW, Jacobsen A, Qvortrup C, Hansen F, Bisgaard C, Baatrup G, Rasmussen P, Pfeiffer P: Longterm results of a phase II trial of high-dose radiotherapy (60 Gy) and UFT/I-leucovorin in patients with non-resectable locally advanced rectal cancer (LARC). Acta Oncol 2008, 47:428-33.

13. Kundel Y, Brenner B, Symon Z, Oberman B, Sadezki S, Koller M, Catane R, Pfeffer R: A phase II study of oral UFT and leucovorin concurrently with pelvic irradiation as neoadjuvant chemoradiation for rectal cancer. Anticancer Res 2007, 27:2877-80.

14. Giralt J, Tabernero J, Navalpotro B, Capdevila J, Espin E, Casado E, Mañes A, Landolfi S, Sanchez-Garcia JL, de Torres I, Armengol M: Pre-operative chemoradiotherapy with UFT and Leucovorin in patients with advanced rectal cancer: a phase II study. Radiother Oncol 2008, 89:263-9.

15. Seck K, Riemer S, Kates R, Ullrich T, Lutz V, Harbeck N, Schmitt M, Kiechle M, Diasio R, Gross E: Analysis of the DPYD gene implicated in 5-fluorouracil catabolism in a cohort of Caucasian individuals. Clin Cancer Res 2005, 11:5886-92.

16. Diasio RB, Johnson MR: Dihydropyrimidine dehydrogenase: its role in 5fluorouracil clinical toxicity and tumor resistance. Clin Cancer Res 1999 5:2672-3.

17. Saif MW, Diasio R: Is capecitabine safe in patients with gastrointestinal cancer and dihydropyrimidine dehydrogenase deficiency. Clin Colorectal Cancer 2006, 5:359-62.

18. Van Kuilenburg ABP, Abreu R, Van Gennip A: Pharmacogenetic and clinical aspects of dihydropyrimidine dehydrogenase deficiency. Ann Clin Biochem 2003, 40:41-5.

19. Miller $A B$, Hoogstraten $B$, Staquet $M$, Winkler $A$ : Reporting results of cancer treatment. Cancer 1981, 47:207-14.

20. Mornex F, Pavy JJ, Denekamp J, Bolla M: Scoring system of late effects of radiations on normal tissues: the SOMA-LENT scale. Cancer Radiother 1997, 1:622-68, article in French.

21. Sobin LH, Wittekind CH: TNM Classification of Malignant Tumours (5th ed). Wiley-Liss; New York; 1997

22. Meterissian S, Skibber J, Rich T, Roubein L, Ajani J, Cleary K, Ota DM Patterns of residual disease after pre-operative chemoradiation in ultrasound T3 rectal carcinoma. Ann Surg Oncol 1994, 1:111-6.

23. Minsky BD, Cohen AM, Enker WE, Paty P: Sphincter preservation with preoperative radiation therapy and coloanal anastomosis. Int J Radiat Oncol Biol Phys 1995, 31:553-9.

24. Morel A, Boisdron-Celle M, Fey L, Soulié P, Craipeau MC, Traore S, Gamelin E: Clinical relevance of different dihydropyrimidine dehydrogenase gene single nucleotide polymorphisms (SNP) on 5fluorouracil tolerance. Mol Cancer Ther 2006, 5:2895-904.

25. Remaud G, Boisdron-Celle M, Hameline C, Morel A, Gamelin E: An accurate dihydrouracil/uracil determination using improved high performance liquid chromatography method for preventing fluoropyrimidines-related toxicity in clinical practice. J Chromatogr B Analyt Technol Biomed Life Sci 2005, 823:98-107.

26. Boisdron-Celle M, Remaud G, Traore S, Poirier AL, Gamelin L, Morel A, Gamelin E: 5-Fluorouacil-related severe toxicity: A comparison of different methods for the pretherapeutic detection of dihydropyrimidine dehydrogenase deficiency. Cancer Lett 2007, 249:271-82.

27. Gamelin E, Boisdron-Celle M, Guérin-Meyer V, Delva R, Lortholary A, Genevieve F, Larra F, Ifrah N, Robert J: Correlation between uracil and dihydrouracil plasma ratio, fluorouracil (5-FU) pharmacokinetic parameters, and tolerance in patients with advanced colorectal cancer: A potential interest for predicting 5-FU toxicity and determining optimal 5-FU dosage. J Clin Oncol 1999, 17:1105-10.

28. Simon R: Optimal two-stage designs for phase II clinical trials. Control Clin Trials 1989, 10:1-10.

29. Kim DY, Jung KH, Kim TH, Kim DW, Chang HJ, Jeong JY, Kim YH, Son SH, Yun T, Hong CW, Sohn DK, Lim SB, Choi HS, Jeong SY, Park JG: Comparison of 5-fluorouracil/leucovorin and capecitabine in preoperative chemoradiotherapy for locally advanced rectal cancer. Int J Radiat Oncol Biol Phys 2007, 67:378-84.

30. Dunst J, Debus J, Rudat V, Wulf J, Budach W, Hoelscher T, Reese T, Mose S, Roedel C, Zuehlke H, Hinke A: Neadjuvant capecitabine combined with standard radiotherapy in patients with locally advanced rectal cancer : mature results of a phase II trial. Strahlentther Onkol 2008, 184:450-6.

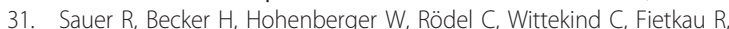
Martus P, Tschmelitsch J, Hager E, Hess CF, Karstens JH, Liersch T, Schmidberger H, Raab R, German Rectal Cancer Study Group: Preoperative chemoradiotherapy for rectal cancer. N Eng J Med 2004, 351:17316-40.

32. Calvo FA, Serrano FJ, Diaz-González JA, Gomez-Espi M, Lozano E, Garcia R, de la Mata D, Arranz JA, García-Alfonso P, Pérez-Manga G, Álvarez E: Improved incidence of pTO downstaged surgical specimens in locally advanced rectal cancer (LARC) treated with induction oxaliplatin plus 
5-fluorouracil and preoperative chemoradiation. Ann Oncol 2006, 17:1103-10.

33. Ryan DP, Niedzwiecki D, Hollis D, Mediema BE, Wadler S, Tepper JE, Goldberg RM, Mayer RJ: Phase I/II study of preoperative oxaliplatin, fluorouracil, and external-beam radiation therapy in patients with locally advanced rectal cancer: Cancer and Leukemia Group B 89901. J Clin Oncol 2006, 24:2557-62.

34. Sebag-Montefiore D, Glynne-Jones R, Falk S, Meadows HM, Maughan T: A phase I/II study of oxaliplatin when added to 5 -fluorouracil and leucovorin and pelvic radiation in locally advanced rectal cancer: a Colorectal Clinical Oncology Group (CCOG) study. Br J Cancer 2005, 93:993-8.

35. Janjan NA, Khoo VS, Abbruzzese J, Pazdur R, Dubrow R, Cleary KR, Allen PK, Lynch PM, Glober G, Wolff R, Rich TA, Skibber J: Tumor downstaging and sphincter preservation with preoperative chemoradiation in locally advanced rectal cancer: the M. D. Anderson Cancer Center experience. Int J Radiat Oncol Biol Phys 1999, 44:1027-38.

36. Chan AK, Wong A, Jenken D, Heine J, Buie D, Johnson D: Post-treatment TNM staging is a prognostic indicator of survival and recurrence in tethered or fixed rectal carcinoma after preoperative chemotherapy and radiotherapy. Int I Radiat Oncol Biol Phys 2005, 61:665-77.

37. Mawdsley S, Glynne-Jones R, Grainger J, Richman P, Makris A, Harrison M, Ashford R, Harrison RA, Osborne M, Livingstone Jl, MacDonald P, Mitchell IC, Meyrick-Thomas J, Northover JM, Windsor A, Novell R, Wallace M: Can histopathologic assessment of circumferential margin after preoperative pelvic chemoradiotherapy for T3-T4 rectal cancer predict for 3-year disease-free survival? Int J Radiat Oncol Biol Phys 2005, 63:745-52.

38. Muthusamy VR, Chang KJ: Optimal methods for staging rectal cancer. Clin Cancer Res 2007, 13:6877-84.

39. Rasheed S, Guenther T, Talbot I, McDonald P, Northover J, Stirling J, Culver L, Glynne-Jones R, Padhani AR: USPIO - enhanced rectal cancer specimen MRI: how well does it correlate with node identification at histopathology? Colorectal Dis 2006, 8:721.

40. Gérard JP, Conroy T, Bonnetain F, Bouché O, Chapet O, Closon-Dejardin MT, Untereiner M, Leduc B, Francois E, Maurel J, Seitz JF, Buecher B, Mackiewicz R, Ducreux M, Bedenne L: Preoperative radiotherapy with or without concurrent fluorouracil and leucovorin in T3-4 rectal cancers: results of FFCD 9203. J Clin Oncol 2006, 24:4620-5.

41. Bosset JF, Collette L, Calais G, Mineur L, Maingon P, Radosevic-Jelic L, Daban A, Bardet E, Beny A, Ollier JC, EORTC Radiotherapy Group Trial 22921: Chemotherapy with preoperative radiotherapy in rectal cancer. $N$ Engl J Med 2006, 355:1114-23.

42. Rodríguez-Ramírez SE, Uribe A, Ruiz-García EB, Labastida S, Luna-Pérez P: Risk factors for anastomotic leakage after preoperative chemoradiation therapy and low RA with total mesorectal excision for locally advanced rectal cancer. Rev Invest Clin 2006, 58:204-10.

43. Urso E, Serpentini S, Pucciarelli S, De Salvo GL, Friso ML, Fabris G, Lonardi S, Ferraro B, Bruttocao A, Aschele C, Nitti D: Complications, functional outcome and quality of life after intensive preoperative chemoradiotherapy for rectal cancer. Eur J Surg Oncol 2006, 32:1201-8.

44. Chen DJ, Nirodi CS: The epidermal growth factor receptor: a role in repair of radiation-induced DNA damage. Clin Cancer Res 2007, 13:6555-60.

45. Bosset JF, Nguyen F, Bosset M, Servagi-Vernat S, Schipman B: Recent advances in the treatment of localized rectal cancer. Curr Oncol Rep 2008, 10:220-4.

\section{Pre-publication history}

The pre-publication history for this paper can be accessed here: http://www.biomedcentral.com/1471-2407/11/98/prepub

doi:10.1186/1471-2407-11-98

Cite this article as: Cellier et al.: Phase II study of preoperative radiation plus concurrent daily tegafur-uracil (UFT) with leucovorin for locally advanced rectal cancer. BMC Cancer 2011 11:98.

\section{Submit your next manuscript to BioMed Central and take full advantage of:}

- Convenient online submission

- Thorough peer review

- No space constraints or color figure charges

- Immediate publication on acceptance

- Inclusion in PubMed, CAS, Scopus and Google Scholar

- Research which is freely available for redistribution

Submit your manuscript at www.biomedcentral.com/submit
C Biomed Central 